\title{
Contraception: School Knowledge and Practical Attitudes in the Urban Commune of Segou, Mali
}

\author{
Tidiani Traoré1*, Cheickna Sylla ${ }^{2}$, Kassoum Sidibé1, Babou Traoréé, Sylvain Guindo1, \\ Adama Coulbaly ${ }^{1}$, Seydouna A. Beye ${ }^{1}$, Seydou Z. Dao ${ }^{3}$, Famakan Kané ${ }^{4}$, Youssouf Traoré5, \\ Ibrahima Téguétés, Moustaph Touré 6
}

${ }^{1}$ Nianankoro Fomba Hospital, Ségou, Mali

${ }^{2}$ Department of Gynecology and Obstetrics, Reference Health Centre in Koutiala, Sikasso, Mali

${ }^{3}$ Department of Gynecology and Obstetrics, Reference Health between the Commune II, Bamako, Mali

${ }^{4}$ Mali Reference Health Centre Bla, Ségou, Mali

${ }^{5}$ Department of Gynecology and Obstetrics, Gabriel TOURE University Hospital, Bamako, Mali

${ }^{6}$ Department of Gynecology and Obstetrics, University Hospital of the Hospital of Mali, Bamako, Mali

Email: ${ }^{\star}$ tidiobongosso@yahoo.fr

How to cite this paper: Sylla, T., Sylla, C., Sidibé, K., Traoré, B., Guindo, S., Coulbaly, A., Beye, S.A., Dao, S.Z., Kané, F., Traoré, Y., Téguété, I. and Touré, M. (2020) Contraception: School Knowledge and Practical Attitudes in the Urban Commune of Segou, Mali. Open Journal of Obstetrics and $G y$ necology, 10, 1370-1380.

https://doi.org/10.4236/ojog.2020.10100126

Received: September 7, 2020

Accepted: October 11, 2020

Published: October 14, 2020

Copyright $\odot 2020$ by author(s) and Scientific Research Publishing Inc. This work is licensed under the Creative Commons Attribution International License (CC BY 4.0).

http://creativecommons.org/licenses/by/4.0/

\section{(c) (i) Open Access}

\begin{abstract}
The aim was to describe aspects of students' knowledge of sexuality and contraception and their sexual behaviour in schools in Ségou, Mali. Materials and Methods: This was a one-pass cross-sectional survey with reasoned choice at the first level and random choice at the second level over a 3-month period from January 2013 to March 2013. Results: The majority of the students involved in our study reside in the commune of Ségou, $90.4 \%$. The average age of our students was 18. The female sex was the most represented in our study with $59.7 \%$. The majority of students had casual sex at $60.3 \%$ and $70.9 \%$ irregularly. The change of sexual partner affected $47.9 \%$ of schoolchildren. Of our sexually active students, $72.6 \%$ had sexual partners and $37.4 \%$ had more than 2 partners. The main sources of information are respectively the media with $72.1 \%$ followed by teachers with $12.9 \%$ and friends with 09.7\%. Among the most well-known contraceptive methods, condoms rank first with $72.6 \%$, followed by injectable with $72.0 \%$. $70.6 \%$ of the population had not yet used a contraceptive method at first sexual intercourse and in $72.9 \%$ of cases was condoms. The most cited source of contraceptive supply is pharmacy with $49.5 \%$ followed by family planning centres and maternity wards at $16.2 \%$ and shops at $16.2 \%$. Conclusion: The referral of young people to approved health facilities for contraception could prevent them from risky sexual behaviours.
\end{abstract}

\section{Keywords}

Teenagers, Youth, School Environment, Contraception, Sexuality 


\section{Introduction}

The concept of reproductive health as defined by the International Conference on Population and Development in 1994 was adopted by Mali. This concept is defined as reproductive health or reproductive health, we mean the general well-being, both physical, mental and social of the human person for everything related to the genital tract, its functions and functioning and not just the absence of disease or infirmity [1]. According to the United Nations Population Fund (UNFPA), reproductive health means that people are able to have a satisfying and unsafe sex life and that they have both the means to procreate and the freedom to decide whether, when and how often they do so [2]. According to the WHO, adolescence and youth range from 10 to 24 years of age [3]. During this phase of life, many changes occur in adolescents who are transitioning to adulthood. In 1994, at the International Conference on Population and Development, it was reported that 1.3 billion women worldwide and of childbearing age had more than 1.2 billion pregnancies which in more than $25 \%$ of cases were unwanted. These unwanted pregnancies resulted in the deaths of nearly 700,000 women, the majority of whom were complicated by complications of unsafe abortions [4].

Mali, for its part, has doubled its population by less than 40 years, from $4,100,000$ in 1960 to $9,800,000$ in 1998 [5]. Women are characterized by very high fertility at a young age (188 to 15 - 19 years) and which increases rapidly to reach its maximum at 25 - 29 years (292 euros), before declining steadily with age. The total fertility rate thus amounts to 6.6 children per woman [6]. However, Mali is one of the countries with one of the lowest contraceptive prevalence, despite efforts in reproductive health. The purpose of this work is to assess students' knowledge, attitudes and practices about contraception; and, above all, to identify barriers to the use of contraception in schools in Ségou.

\section{Objectives}

To describe aspects of students, knowledge of sexuality and contraception and their sexual behaviour in schools in Ségou, Mali.

\section{Materials and Methods}

This was a one-pass cross-sectional survey with reasoned choice at the first level and random choice at the second level over a 3-month period from January 2013 to March 2013. The study population was students from high schools and vocational schools in the city of Ségou. The sample size was calculated using the following formula: N-4.P.Q/I2 P-represents the prevalence of use of contraceptive methods by students in previous studies (5\%). Q-1-P-0.95 I-the desired accuracy at $2 \%$ No. $4(0.05 \times 0.95) / 475(0.02) 2$. This minimum size is 475 students and for greater representation we have retained 1000 students. Inclusion criteria: Girls and boys aged 13 to 26 who attended high schools and vocational schools in the city of Ségou and agreed to participate in the study. Non-inclusion crite- 
ria: Girls and boys from high schools and vocational schools who did not agree to participate in the study. Data collection: Data support was a questionnaire administered to the student at the time of the survey. The questionnaire consisted of three parts: Student Identification; knowledge of family planning, identification of risky behaviours. The data collection technique was a direct interview between the student and the investigator. The data were collected from an individual questionnaire developed for this purpose. Data processing and analysis: Data entry and analysis were done on Microsoft Word and on co info (version 2000).

\section{Results}

\subsection{Socio-Demographic Characteristics}

The majority of the students involved in our study reside in the commune of Ségou, $90.4 \%$. The average age of our students was 18 . The female sex was the most represented in our study with $59.7 \%$. High school students were represented by $75.9 \%$ of the population surveyed compared to $24.1 \%$ students from vocational schools. In our study, among $10.9 \%$ of the married $57.8 \%$ were female. Table 1 and Table 2 show us the epidemiological characteristics of schoolchildren.

Table 1. Epidemiological characteristics of schoolchildren in the urban commune of Ségou in Mali in 2013.

\begin{tabular}{|c|c|c|}
\hline Age in Year & Staff & Frequency (\%) \\
\hline 13 - 15 years & 75 & 7.5 \\
\hline $16-20$ years & 795 & 79.5 \\
\hline 21 - 26 years old & 130 & 13.0 \\
\hline \multicolumn{3}{|l|}{ Sex } \\
\hline Female & 597 & 59.7 \\
\hline Male & 403 & 40.3 \\
\hline \multicolumn{3}{|l|}{ Marital status } \\
\hline Single & 891 & 8900.1 \\
\hline Bride & 109 & 10.9 \\
\hline \multicolumn{3}{|l|}{ Residence } \\
\hline City of Ségou & 904 & 90.4 \\
\hline Out of the city of Ségou & 96 & 9.6 \\
\hline
\end{tabular}




\subsection{Sexual Behaviour}

The majority of girls had their first period at an age between 13 - 15 years of age or $68.3 \%$. $60.3 \%$ of students had had casual sex and in $70.9 \%$ had an irregular sexual relationship. In our study, $47.9 \%$ of schoolchildren had changed sexual partners. In our series, the time between menarche and first sexual intercourse was on average 3 - 4 years for $33.9 \%$ of girls. It was less than 1 year for $6.9 \%$ of girls. Of the $69.2 \%$ of schoolchildren who were aware of the fertility period only $10.8 \%$ knew the possibility of pregnancy from the first sexual encounter. Table 3 and Table 4 show the sexual behaviour of schoolchildren.

Table 2. Epidemiological characteristics of schoolchildren in the urban commune of Ségou in Mali in 2013.

\begin{tabular}{cccc}
\hline \multicolumn{1}{c}{ Busy class } & & Staff & Frequency (\%) \\
\hline High school & 10 th & 230 & 23.0 \\
& 11 th & 284 & 28.4 \\
& 12th & 245 & 24.5 \\
\hline Professional school & 1st year & 77 & 7.7 \\
& 2nd year & 60 & 6.0 \\
& 3rd year & 73 & 7.3 \\
\hline
\end{tabular}

Table 3. Sexual behaviour of schoolchildren in the urban municipality of Ségou, Mali in 2013.

\begin{tabular}{ccc}
\hline First sexual intercourse & Staff & Frequency (\%) \\
\hline Yes & 952 & 95.2 \\
Not & 48 & 4.8 \\
\hline Age first sexual intercourse & 24 & 2.5 \\
\hline $10-13$ years & 362 & 38.0 \\
$14-17$ years & 309 & 32.5 \\
$18-21$ years & 09 & 0.9 \\
$22-26$ years & 248 & 26.1 \\
Unknown & & 60.3 \\
\hline Programmed character & 574 & 39.7 \\
\hline Not Programmed & 378 & \\
\hline
\end{tabular}


Table 4. The sexual behaviour of students (continued) by schoolchildren in the urban commune of Ségou in Mali in 2013.

\begin{tabular}{ccc}
\hline Regularity of reports & Staff & Frequency (\%) \\
\hline Irregular & 675 & 70.9 \\
Regular & 277 & 29.1 \\
\hline Changing sexual partners & 614 & 61.4 \\
No change & 185 & 18.5 \\
Once & 83 & 8.3 \\
Twice & 118 & 11.8 \\
\hline Three Times and More & & \\
\hline
\end{tabular}

\subsection{Risky Sexual Behaviour}

More than half of our sexually active students, $72.6 \%$, had a sexual partner and $37.4 \%$ had more than 2 sexual partners. Table 5 represents data on school-risk sexual behaviour.

\subsection{Sources of Information}

The main sources of information are the media $(72.1 \%)$ respectively followed by teachers $(12.9 \%)$ and friends $(09.7 \%)$. Table 6 shows the source of information for schoolchildren.

\subsection{Practical Knowledge and Attitudes}

The majority of respondents, $93 \%$ say they have heard of family planning (PF). Among the most well-known contraceptive methods, condoms rank first with $72.6 \%$ of students, followed by injectables with $72.0 \%$ regardless of gender and age. The majority of students (70.6\%) in our study had not yet used a contraceptive method at first sexual intercourse. Of those surveyed who used a contraceptive method, $72.9 \%$ had used condoms. Contraception is known in schools and practical attitudes are most often problematic in its use. Table 7 and Table 8 present schoolchildren's knowledge of the existence of contraceptive methods and the use of methods at first sexual intercourse.

Table 9 shows us the reasons for school use and non-use of contraceptives.

\subsection{Sources of Supply}

The main source of supply of contraceptive methods was the pharmacy represented by $49.5 \%$ of the workforce followed by the $16.2 \%$ FP centers, maternity wards and shops. Table 10 shows us the source of contraceptive supplies for schoolchildren. 
Table 5. At-risk sexual behaviours of schoolchildren in the urban commune of Ségou in Mali in 2013.

\begin{tabular}{ccc}
\hline Knowledge of the fertility period & Staff & Frequency (\%) \\
\hline Not & 308 & 30.8 \\
Yes & 692 & 69.2 \\
\hline $\begin{array}{c}\text { Possibility of pregnancy from } \\
\text { first sexual intercourse }\end{array}$ & \\
\hline Not & 892 & 89.2 \\
Yes & 108 & 10.8 \\
\hline Number of sexual partners & & \\
\hline 1 partner & 691 & 72.6 \\
2 partners & 160 & 16.8 \\
3 partners and more & 101 & 10.6 \\
\hline
\end{tabular}

Table 6. A source of information for schoolchildren in the urban commune of Ségou in Mali in 2013.

\begin{tabular}{ccc}
\hline Source of information & Staff & Frequency (\%) \\
\hline Friends & 90 & 9.7 \\
Media & 671 & 72.1 \\
Teachers & 120 & 12.9 \\
Parents & 49 & 5.3 \\
\hline
\end{tabular}

Table 7. Knowledge of the existence of school contraceptive methods in the urban commune of Ségou in Mali in 2013.

\begin{tabular}{|c|c|c|c|c|}
\hline \multirow{2}{*}{$\begin{array}{l}\text { Kontraceptive methods } \\
\text { Methods/contraceptives }\end{array}$} & \multicolumn{2}{|c|}{ Yes } & \multicolumn{2}{|c|}{ Not } \\
\hline & Staff & Percentage & Staff & Percentage \\
\hline Periodic abstinence & 665 & 66.5 & 335 & 33.5 \\
\hline Female Preservative & 695 & 69.5 & 305 & 30.5 \\
\hline Male Preservative & 726 & 72.6 & 274 & 27.4 \\
\hline Spermicide ovule & 383 & 38.3 & 617 & 61.7 \\
\hline Vaginal diaphragm & 415 & 41.5 & 585 & 58.5 \\
\hline Implant & 367 & 36.7 & 633 & 63.3 \\
\hline Pill & 658 & 65.8 & 342 & 34.2 \\
\hline Emergency Contraception & 313 & 31.3 & 687 & 68.7 \\
\hline IUD/STERILE & 318 & 31.8 & 682 & 68.2 \\
\hline Female sterilization & 594 & 59.4 & 401 & 40.1 \\
\hline Male sterilization & 588 & 58.8 & 492 & 49.2 \\
\hline Necklace & 607 & 60.7 & 393 & 39.3 \\
\hline
\end{tabular}


Table 8. Contraceptive method used at first sexual intercourse by schoolchildren in the urban commune of Ségou in Mali in 2013.

\begin{tabular}{ccc}
\hline $\begin{array}{c}\text { Types of contraceptive methods at } \\
\text { first sexual intercourse }\end{array}$ & Staff & Frequency (\%) \\
\hline Periodic Abstinence & 7 & 2.5 \\
Necklace & 2 & 0.7 \\
Implant & 7 & 2.5 \\
Injection & 30 & 10.7 \\
Ovule Spermicide & 1 & 0.3 \\
Pill & 24 & 8.6 \\
Female Preservative & 5 & 1.8 \\
Male Preservative & 204 & 72.9 \\
\hline
\end{tabular}

Table 9. Reasons for contraceptive use and non-use by schoolchildren in the urban commune of Ségou in Mali in 2013.

\begin{tabular}{ccc}
\hline Reasons for use & Staff & Frequency (\%) \\
\hline Imposed by partner & 34 & 12.1 \\
Pregnancy prevention & 216 & 77.1 \\
STI prevention & 30 & 10.7 \\
\hline Reasons for not using & & \\
\hline Lack of willpower & 357 & 53.1 \\
Lack of information & 311 & 46.3 \\
Financial problems & 4 & 0.6 \\
\hline
\end{tabular}

Table 10. Source of school supplies for contraceptives in the urban commune of Ségou in Mali in 2013.

\begin{tabular}{ccc}
\hline Place of sourcing Contraceptives & Staff & Frequency (\%) \\
\hline Pharmacy/Earth & 14 & 1.5 \\
Friends & 101 & 10.7 \\
Neighbourhood shop & 104 & 11.2 \\
PF Center & 100 & 10.6 \\
Maternity & 151 & 16.2 \\
Pharmacy & 460 & 49.5 \\
\hline Time between menarche-1st sexual report & & 6.9 \\
\hline 1 year & 40 & 23.1 \\
1 - 2 years & 134 & 33.9 \\
3 - 4 years & 196 & 12.8 \\
Sup 5 years old & 74 & 23.3 \\
\hline Unknown & 135 & \\
\hline
\end{tabular}




\section{Discussion}

\subsection{Socio-Demographic Characteristics}

\subsubsection{Socio-Demographic Characteristics}

In the literature, the average ages found by the authors are superimposed. In Mali, in Sikasso MAIGA O. L. [7] reports an average age of 17.25 years, SANGARE A. K. [8] in Bamako also reports an average age of 17.5 years. The average age of our students was 18 in our series. The majority of the students involved in our study resided in the city of Ségou, $90.4 \%$. The female sex was the most represented in our study with $59.7 \%$ despite the low overall enrolment rate of girls. High school students were represented with $75.9 \%$ of the population surveyed compared to $24.1 \%$ students from vocational schools. The organization of African societies with its cultures and customs makes us observe that early marriage is still relevant through our rate of married girls of $10.9 \%$, generally hindering the academic career of its daughters.

\subsubsection{Risky Sexual Behaviour}

According to the literature, several authors give different ages compared to first sexual intercourse. In the UNAZIGO et al. [9] study $40 \%$ were sexually active. Among sexually active students in the sample (38\%) had had their first sexual intercourse between the age of 14 and 17. In network 2000 [10], the authors indicate that in Chile studies have found that $1 / 3$ of adolescents had their first sexual intercourse before the age of 15. KAMTCHOUING et al. [11] found that $56 \%$ of their sample had their first sexual intercourse before the age of 15 . It was between 15 and 17 years old for SIDIBE et al. [12]. In Zimbabwe, the age at first sexual intercourse was 9 years [13], in Burkina Faso it is around the age of 15 [14]. In Niger, it was 12 years old [14]. In Senegal, 27\% of adolescents reported having had their first sexual intercourse before the age of 15 in 1992, according to a study by the United Nations Development Fund (UNFPA) [14]. In our series, he was between 14 and 17 years old. Of the sample, $95.2 \%$ of students had had their first sexual intercourse and $40.5 \%$ before 17 years.

According to the WHO, anyone who has had a single sexual partner would be considered a low risk of being infected by sexually transmitted infections and the behaviour is only at high risk if the person has had more than two sexual partners. The risk of being contaminated in schools is high by the results reported by the literature. Multiple sexual partners are vectors of HIV/AIDS transmission and a factor promoting cervical cancer (human papilloma virus). This risk of contamination by sexually transmitted infectious diseases is very high in the context of unprotected casual sex, change of sexual partner, multiple sexual partners, especially since this risk is ignored by the majority of these students. $60.3 \%$ of students in our study had had casual sex and $47.9 \%$ of schoolchildren had changed sexual partners. In addition to these risks, there is also the risk of early pregnancy, clandestine induced abortions, dropping out of school. Fortunately, $69.2 \%$ of schoolchildren in our series say they have heard about the fertil- 
ity period and $10.8 \%$ of schoolchildren say they have heard about the possibility of pregnancy from the first sexual intercourse through awareness campaigns around family planning and fertility. Thus among our sexually active students $72.6 \%$ had a sexual partner considered low risk behaviour and $10.6 \%$ had more than 2 partners considered high risk behaviour. Authors like SACKO-D [15] and CISSE A [16] were found $11.45 \%$ and $9.17 \%$ of sexually active students respectively to be at low risk. Similarly, SACKO-D [15], CISSE A. [16] and SANGARE A. K. [8] found $73.12 \%$ respectively; $60 \%$ and $67 \%$ of sexually active students had high-risk behaviour. Our high risk rate of $10.6 \%$ is superimposed on that of BERTHE B. B. [17] who found $8 \%$ high-risk behaviour.

\subsection{Sources of Information}

The main source of information was the media, with a rate of $72.1 \%$ followed by teachers or $12.9 \%$ and friends or $09.7 \%$. As with other studies including SIDIBE et al. [12], SANGARE A. K. [8], and BERTHE B. [17]), the media have been the main source of information for adolescents. SIDIBE et al. [12] found $96.3 \%$ for the media, $72.4 \%$ for friends and $19.6 \%$ for parents. FayE [18] had instead found the following order: the media, the school, the counselling centre for teenagers. We think like BERTHE B. [17] that contraception, which is a subject related to sexuality, is considered taboo in our society. They concluded that the family is a rare source of family planning information.

\subsection{Practical Knowledge and Attitudes}

The majority of respondents, $93 \%$ say they have heard of family planning (PF). This result is confirmed by other studies such as: BOMIA M. A. D. [19], conducted in the district of Bamako in school that found 93.8\%. And a school-based study conducted in Bamako by CAMARA M. [20] found that $73.10 \%$ of schoolchildren had heard of PF. Among the most well-known contraceptive methods, condoms rank first with $72.6 \%$ of students, followed by injectables with $72.0 \%$ regardless of gender and age. SIDIBE et al. [12] found $96.9 \%$ and $91.6 \%$ for condoms and pills respectively. Other authors found comparable results, as well as SACKO-D [15]; and MAIGA-K [21] in their studies found in Mali, the same results with the most well-known methods: pills and condoms. In its study, SANGARE A. K. [8] had $31 \%$ of its respondents who claimed to have used a contraceptive method, while $42.6 \%$ of students said they had used condoms. The majority of students $(70.6 \%)$ in our study had not yet used a contraceptive method at first sexual intercourse. Of those surveyed who had used a contraceptive method, $72.9 \%$ had used condoms.

Elsewhere BOMIA-M [19] found that $21 \%$ of his sample had used a condom at the first report. A study carried out in 6 schools (secondary level) in Côte d'Ivoire [22] found that condoms were the most used by adolescents with $38.06 \%$. Regarding the reasons for the use of a contraceptive method at first sexual intercourse respectively $77.1 \%$ and $10.7 \%$ of respondents thought it was to 
avoid pregnancy and STIs. Similar results are found by SANGARE A. K. [8] and BERTHE B. [17]. Lack of willpower and information are the most cited causes of non-use of contraception with $51.3 \%, 46.3 \%$ respectively. As evidenced by SANGARE A. K. [8], the lack of information or a lack or malfunction of youth-friendly FP services attests to the low use of contraceptive methods.

\subsection{Source of Supply}

Various sources of contraceptive supply have been reported. Among them the pharmacy comes first with $49.5 \%$ followed by family planning centers $16.2 \%$ and $16.2 \%$ for shops as well. BERTHE B. B. [17] found $89.6 \%$ for pharmacy and $18.8 \%$ for health centre.

\section{Conclusion}

The referral of young people to approved health facilities for contraception could prevent them from risky sexual behaviours.

\section{Authors' Contributions}

All the authors participated in the writing of the manuscript. They all approve the final version of the manuscript.

\section{Conflicts of Interest}

The authors declare no conflicts of interest regarding the publication of this paper.

\section{References}

[1] Pro Fam/USAID/PSI MALI (2007) Contraception Technology/Clinical PF. Reference Manual. January.

[2] Robert A. Hatcher. Contraceptive Technology, Web. http://www.managingcontraception.com

[3] Oms, G. (1994) Not/Dsf/Oms. Pregnancy and Abortion during Adolescence: Report of a WHO Expert Meeting. Technical Report Series, No. 583, 1975, 10.

[4] Daulaire, N., et al. (2002) Promises to Keep. The Toll of United Pregnancies on Women Live in the Developing World. Global Health Council, Washington DC.

[5] Agi, Sharing Responsibility (1999) Women, Society and Abortion Worldwide. Alan Guttmacher, Institute, New York, 51.

[6] Reynolds, H.W., Wong, E.L. and Tucker, H. (2006) Teenagers Use of Maternal and Child Health Services in Developing Countries. International Family Planning Perspectives.

[7] Maiga, O.L. (2001) Knowledge, Attitude and Sexual Behaviour in School: Bougouni Secondary Normal School and Mon Lord de Mont Clos High School in Sikasso. Thesis Medicine, FMPOS, Bamako, No. 79, 55p-annexs.

[8] Sangare, A.K. (2003) Knowledge, Attitudes and Practices of Schoolchildren at Three High Schools in Bamako Regarding Family Planning and STIs/AIDS. Thesis Medicine, Bamako, No. 6, 162 p.

[9] Amazigo, U., Silva, N., Kaufman, J. and Obikeze, D. (1997) Sexual Activity and 
Knowledge and Practice of Contraception among Nigerian High School Students. International Perspectives on Family Planning, Special, 15-20.

[10] Network Family Health International (1994) The Parents of Tomorrow. Flight 9 No. 4, October 1994, 8-15.

[11] Kamtchouing, P., Takougang, I., Ngoh, N. and Yakam, I. (1997) The Sexuality of Adolescents in Schools in Yaounde, Cameroon. Contraception, Fertilité, Sexualité, 25, 798-801.

[12] Sidibe, T. (2006) Knowledge and Practices of Students at a High School in Bamako Regarding Contraception and Prevention of STIs/AIDS. Medical Mali, N1, 39-42.

[13] Onusida (2009) Update on the AIDS Epidemic. 52 p.

[14] Cerpod (1996) Regional Study on Adolescent Reproductive Health in the Sahel "Focus Group" and One-on-One Interview in Burkina Faso, Mali and Niger. Research Report; Number One.

[15] Sacko, D. (2002) LBAD Adolescent Knowledge, Attitudes and Practices on Family Planning, STDs and AIDS. Thesis Med. Bko. No. 62.

[16] Cisse, A. (1993) Knowledge and Sexual Behaviour of 15-29 Year Olds on STDs-AIDS in Bamako. Memo. Med. Quebec. 1993. No. 117.

[17] Berthe, B.B. (2000) Knowledge, Attitude, Practice of Adolescents at Askia Mohamed High School in Family Planning, Sexually Transmitted Diseases and AIDS. Thesis Med., No. 47 Bamako, Mali.

[18] Faye, M. (2005) Knowledge, Attitudes and Practices Regarding Adolescent Reproductive Health at the Anonymous and Free CDVAA Screening Centre in Pikine-Guédiawaye. Master's Thesis, Cheick Anta Diop University, Dakar, 73 p.

[19] Bomia, M.A.D. (2004) Knowledge, Attitude and Practice on Reproductive Health in Schools (2nd Basic and High School) in Bamako from March to June 2004. Medicine Thesis, No. 17, Bamako, Mali.

[20] Camara, M. (1992) Teenage Contraception. Med. Bamako Thesis.

[21] Maiga, K. (1994) Light on Sex Life. Edition. Jamana Edition. Bko No. 6686.

[22] Guie, P., Tegnan, J., Amoumatacky, A., N’guessan, E., Osondu, J.N., Anongba, S. and Toure Coulibaly, K. (2001) Contraception in Schools Based on a Survey of 3013 Students in 6 Schools in Côte D'Ivoire. 